\title{
Editorial
}

This issue of Ushus - Journal of Business Management comes with four articles; one each on private label products, investment perception, equity risk premium and a case study on Jewellery industry in West Bengal.

Ritu Srivastava studies private label motivators and product category association. The findings of the study indicate that product category does have an intervening role in the customer's private label purchase decision.

Sri SukantaSaha takes a look at expanding growth pole and thriving SEZ in the Bengal Gems and Jewellery Industry. The case study focuses on two specific sites of the Gems and Jewellery industry in West Bengal, namely Domjur (Howrah) and Manikanchan, Rajarhat, Kolkata. The study aims to search the reasons in the context of classical and neo-classical Location Economics literature.

The paper of P Hemavathy and S Gurusamy is on perception of the Indian working women considering equity as an investment avenue. It attempts to study the influence of demographic variables on the reasons which facilitate the stock market participation and reasons for resistance among the Indian working women to make equity investment.

Santosh Kumar studies equity risk premium through a cross country analysis on return behaviour. His research captures the differences in the ex-post behaviour of equity risk premium between developed and emerging markets. Further, an investigation has been made into the impact of global integration on the ERP across G7 countries and 7 emerging countries. The analysis has shown a decline in the ERP of developed nations and an upward trend in emerging markets over the chosen sub-sample period.

Wish you fruitful reading, and anticipate creative and critical feedback.

\section{Shivi Khanna}

Issue Editor 
